\title{
Black Music is American Music: Learning Underrepresented Aspects of Black History in College through Critical Race Media Literacy
}

\author{
Tiffany Mitchell Patterson \\ West Virginia University \\ U. S. A. \\ Christine McWhorter \\ Howard University \\ U. S. A.
}

\begin{abstract}
The New York Times 1619 Project materials on American popular culture were presented to college students at a Historically Black University \& College (HBCU) and a Predominantly White Institution (PWI). Guided by Critical Race Media Literacy, we employed quantitative and qualitative analysis to explore the knowledge-based and emotional responses to Black historical media. The findings suggest that HBCU and PWI students had similar levels of prior knowledge and experienced disparate emotional responses to the material. Overall, both HBCU and PWI students' knowledge increased following the study, which highlights the potential of educational media to amplify and engage students in underrepresented histories.
\end{abstract}

KEYWORDS: Black History, Black Music, Critical Race, Media Literacy, Higher Education

\author{
Theoretical Framework \\ Methodology \\ Quantitative Findings \\ Qualitative Findings \\ Discussion \\ Conclusion \\ Notes \\ References \\ Author Contact
}

Depending on the institutional context, college students could have either a plethora or lack of opportunities to engage deeply with diverse Black histories. Exposure to Black histories in higher education varies by institution. Unlike Predominantly White Institutions (PWIs), Historically Black Colleges \& Universities (HBCUs) were created to affirm Black racial identities and disrupt White negative perceptions of Blackness (Arroyo \& Gasman, 2014). Given their fundamental purpose, students who attend an HBCU are immersed in an institutional culture that centers Blackness and may thus have more access to coursework, university-wide programming, and faculty expertise in diverse Black histories. Alternatively, access to diverse Black histories for students attending a 
PWI may be relegated to a course, a designated Black Studies major or minor, a center, and/or limited university programming related to the Black experience.

In the media-rich and media-saturated world of today, popular culture and visual media outlets have been influential in providing another space for Black historical study (King, 2017b). Popular media can provide an avenue for college educators across disciplines and institutional contexts to engage students in a critical exploration of diverse Black histories, race, and racism. Education efforts that address the media's role in perpetuating stereotypes help to mitigate the effects of negative exposure or narrow media depictions of social groups and will hopefully encourage positive media influences that include increased exposure to non-stereotypical media depictions (Scharrer \& Ramasubramanian, 2015).

With the pervasiveness of multiple platforms of media positioning audiences as constant consumers of pop culture texts, messages are frequently viewed and accepted without examination. Racial identity is a complex, intricate issue, generally defined as "a person's sense of self or self-image" (Akerlof \& Kranton, 2010). A person's identity is "bound to social categories; and individuals identify with people in some categories and differentiate themselves from those in others" (p. 720). Racial identity is further explained by the psychological connection a person feels toward their racial group, in addition to the political and historical implications connected with that identity. In the case of Black Americans, societal meanings attached to Blackness and perpetuated in the media are often negative and juxtaposed to positive or neutral meanings that are connected with Whiteness. Black people are often categorized as lazy, unintelligent, or violent, for example, while Whites are seen as industrious, intelligent, and well-intentioned (Durden, Dooley, \& Truscott, 2016). This is especially problematic since media research shows that filmgoers and television viewers often subscribe to the ideology that is purported in the movies and shows they watch (Sellnow, 2017).

Over the past decade, teachers, and college educators in the U.S. have been encouraged to teach media literacy, which is the ability to analyze and critique media (Solórzano \& Yosso, 2002). Media literacy can also be employed as a strategy to engage in critical conversations regarding social issues (Bergstrom, Flynn, \& Craig, 2018). It is imperative that scholars and teachers include Critical Race Media Literacy (CRML), a subset of media literacy that draws on Critical Race Theory (Bell, 1992), in their work. CRML engages in the critical examination of race and privileges the stories of people of color through media. Educators can use media to provide a heuristic for students to explore and interrogate the roles of race and racism (King, 2017b). Critical Race Media Literacy can serve as a powerful analytical tool for college educators to understand race and utilize popular culture media to promote anti-oppressive education (Agoosto, Karanxha, \& Cobbs-Roberts, 2016).

An ongoing initiative from The New York Times (NYT), titled The 1619 Project, was launched in August 2019 to commemorate the 400th anniversary of American enslavement. This popular editorial project created by renowned journalist Nikole Hannah-Jones features a collection of essays with accompanying podcasts that reframe the country's history by placing the consequences of slavery and the contributions of Black Americans at the very center of our national narrative (The 1619 Project, 2019). 
The NYT 1619 Project offers a way for college educators to present nuanced Black histories to students.

This study utilized a specific NYT 1619 Project media article and podcast written by Wesley Morris (2019, August 14) focused on the historical contributions of Black Americans in popular American music from minstrel shows, jazz, funk, and hip hop to bluegrass, country, and rock. As Morris (2019) describes in the NYT 1619 Project, "For centuries, Black music became the sound of complete artistic freedom. The sound of American music. No wonder everybody is stealing it" (p. 60). While Blackface minstrelsy was a major focus of the article/podcast, Black contributions to various music genres were discussed. In this context, we position Black music as an underrepresented aspect of Black history with which college students may be unfamiliar. In our study, we explore how college students at PWIs \& HBCUs respond emotionally when learning about American popular music through the NYT 1619 Project materials.

\section{Theoretical Framework}

The theoretical framework of this study is rooted in the body of work surrounding Critical Race Media Literacy (CRML). Critical Race Media Literacy challenges students to cultivate a critical understanding of the problematic race-related issues in media. (Yosso, 2002). The theory draws on the foundations of Critical Media Literacy while also integrating vital components of Critical Race Theory.

Critical Media Literacy (CML) is the "ability to decode and critique mass media texts while centralizing 'ideology' critique and analyzing the politics of representation of crucial dimensions of gender, race, class, and sexuality" (Kellner \& Share, 2007, p. 8). CML operates under two main assumptions. First, media texts, including print, audio, visual, and interactive platforms, help construct users' understanding of political, social, and economic structures (Alvermann, Moon, \& Hagood, 1999; Luke 2004; Kellner \& Share, 2009). Second, developing CML consciousness empowers media users to confront the power structures prevalent in media (Alvermann \& Hagood, 2000).

Critical Race Theory (CRT) is a theoretical framework that asserts that race and racism are permanent functions of American life. CRT posits that various forms of oppression matter in the interactions among policy, people, and places. CRT developed from Critical Legal Studies during the 1970s and1980s as a critique of the racially biased economic, political, and legal system (Bell, 1992; Delgado \& Stefancic, 2017; Taylor, Gillborn, \& Ladson-Billings, 2009). The theory highlights the pervasive nature of race and racism and posits that a person's lived experience is deeply affected by those issues. Over the last few decades, CRT has been used in multiple disciplines, such as education (Dixson \& Anderson, 2018; Ladson-Billings \& Tate, 1995; Solórzano \& Yosso, 2002), sociology (Christian, Seamster, \& Ray, 2019), and media studies (Agoosto, Karanxha, Cobbs-Roberts, 2016, Hawkman \& Van Horn, 2019; Shear, 2018) to examine racism and institutionalized injustices. Scholars further suggest that there are at least five tenets of CRT that can be used as a framework to inform CRT research in education (Solórzano, Villalpando \& Oseguera, 2005; Yosso, 2005). The five tenets are (a) the centrality of race and racism, (b) the challenge to dominant ideology, (c) a commitment to social justice, (d) a centrality of experiential knowledge, and (e) the interdisciplinary perspective. 
Yosso's (2002) pioneering work merged CRT with Critical Media Literacy to form Critical Race Media Literacy (CRML). Recent studies have used CMRL as a framework for examining methods of increasing critical understanding of systemic racial inequities as portrayed in various media. For instance, Hawkman and Shear's (2017) work outlined pillars of CRML that were incorporated in social studies lessons. These pillars are confrontation, interrogation, and navigation. Confrontation occurs when students are exposed to problematic media representation. In this stage, teachers embolden students to confront internal bias and desensitization, built up from years of media exposure. The next stage is interrogation, where teachers encourage students to challenge their previously held racial beliefs. Finally, navigation occurs when students challenge prevailing narratives using knowledge and agency gained in the previous two stages.

\section{The Effects of Media Messages}

Proponents of CRML argue that the material consequences of images and portrayals cannot be ignored. Critical media pedagogies situate students as critical users of pop culture texts and help them discern how media privilege certain groups and marginalize others (Morrell, 2002). As digital media have become ubiquitous in students' lives, the need for CRML is achingly apparent. Visual media has become a vehicle for communicating, learning and navigating students' reality (Potter, 2013). Media in various forms profoundly affect users. While digital media platforms like podcasts and web articles are often sought out for entertainment, they also have immense potential to educate or miseducate readers/listeners. An audience member's attitudes, ideals, and actions are molded by information sources when they encounter mediated themes and ideas, whether intentionally or unintentionally (Buckingham, 2013; Considine, 2002). Mainstream messages perpetuate stereotypes by upholding traditional racist, sexist, or classist institutional social norms (Alvermann \& Hagood, 2000).

Opportunities for Critical Race Media Literacy in education are far reaching. Beyond helping students understand stereotypes and inaccurate portrayals in media messages, developing CRML opens students' eyes to the subjective nature of "worlds" painted by media creators. These mediated worlds reflect structural characteristics of students' lives that may have previously gone unnoticed. Upon encountering these worlds from a CRML perspective, students are urged to confront the disparate realities assigned to people based on race, gender, and class. Students evaluate these messages and contemplate whose ideas, values, and beliefs are propagated and whose are left out; they understand whose narratives are mainstreamed and whose are sidelined (Considine \& Haley, 1999; King 2017a). It is the development of an analytical view of societal construction that makes CRML so significant. The formation of a nuanced understanding of privilege and racism is vitally important to examining and recognizing systems of power, whether they appear in a mediated message, the government, the professional realm, or relationships. When messages are filtered through a CMRL perspective, students understand institutional inequities that result from cultural norms, practices, and beliefs. They are often empowered to confront inequitable structures anywhere they exist (Buckingham, 2013; Hawkman \& Shear, 2017; Luke, 2012). 


\section{Critical Race Media Literacy and Historical Pop Culture}

Concerning pedagogy and curriculum, college educators must remember to choose what is beneficial to students' study. Using pop culture texts can make information relatable for some students who find themselves outside of the traditionally privileged group of students. Morrell notes, "Often, the failure of urban students to develop 'academic' literacy skills stems not from a lack of intelligence but from the inaccessibility of the school curriculum to students who are not in the 'dominant' or 'mainstream' culture" (Morrell, 2002, p. 72). The use of relatable texts is vital because viewers have an important stake in the scrutiny of these narratives. Since pop culture often serves as public pedagogy (Sellnow, 2017), it frequently functions as an avenue through which people learn about the historical contributions of Black Americans. CRML serves as a lens through which students can critique the way historical representations of Black contributions have been presented and assert an agentic, critical role in ascertaining Black American historical significance.

Notably, racially minoritized groups are often depicted in a negative or culturally inaccurate manner, especially in the context of historical texts (Cortes, 1987). Therefore, the development and use of texts that accurately depict historical contributions of marginalized groups should be prioritized. Moreover, Black history in state-mandated curriculum is often limited in scope and typically presents singular narratives of a few "heroes." These narratives usually meet the criteria of liberal multiculturalism, where the narratives presented are safe and sanitized, devoid of critical and racial analysis of Black history (King, 2019). When accurately representative materials are used, individuals of all backgrounds can connect with characters, feel proud of their heritage, and find new and exciting ways to learn and display what they have learned (Morrell \& Duncan-Andrade, 2006). In addition, the regular use of these films, shows, and songs helps students understand how to critically challenge historical media texts featuring people of various backgrounds, thus creating an educational norm that accepts and encourages multiple interpretations of media.

One of the primary functions of media educators is to ensure that our students develop this vital skill set (Alvermann \& Hagood, 2000). Recent scholarship on critical media literacy and pop culture pedagogies among students and adults has increased over the past two decades (Gainer, 2012; Guy, 2007; Rodesiler, 2010; Semali, 2018); however, the need for CRML teaching and scholarship remains vast. As more educators on the K-12 and the postsecondary levels incorporate these topics into their teaching, hopefully future research will continue to emphasize the importance of pop culture texts in the analysis of systems of power. Given the lack of depth and breadth of Black history education in $\mathrm{K}-12$ and college classrooms, we posit that CRML can serve as a framework to center diverse Black histories.

This study examines the level of knowledge and emotional responses of college students in different institutional contexts (HBCU \& PWI) when engaging with a selected 1619 Project material (article and podcast on music in American popular culture). Four research questions were posed. First, is there a relationship between the students' institution type and their emotional responses to the NYT 1619 media? Second, is there a relationship between students' institution type (HBCU or PWI) and pre-test score level? Third, is there a relationship between students' institution type (HBCU or PWI) and post- 
test score level? And finally, how do college students experience learning underrepresented aspects of Black history through NYT 1619 media based on institutional affiliation (HBCU or PWI)?

\section{Methodology}

This study was conducted at two U.S. public universities, a Historically Black College \& University (HBCU) and a Predominantly White Institution (PWI) during the fall semester of 2019. Both quantitative and qualitative data were collected through a survey. This study included a pre and post assessment to test students' knowledge of Black music history. We also used a Likert scale survey to measure emotional responses to the NYT 1619 Project media. Additionally, a thematic analysis of six open-ended responses to the quantitative survey was conducted to illustrate the quantitative data and offer further insight. Thematic analysis is a useful method for examining the perspectives of different research participants, highlighting similarities and differences, and generating unanticipated insights (King, 2004; Nowell et al., 2017).

\section{Participants}

A sample of college students at an HBCU and a PWI in the United States responded to the surveys, which were developed and conducted using the Google Forms platform: 43 respondents took the pre-test and 37 respondents took the post-test and answered six open-ended questions based on the 1619 Project materials. Of the 43 students, roughly $80 \%$ were college students enrolled at the $\mathrm{HBCU}$, and $20 \%$ were college students enrolled at the PWI. There were no financial incentives for taking part in this study.

Students of different racial identities attend both $\mathrm{HBCU}$ and PWI institutions. Both HBCU and PWI students have undergone the social and emotional developmental process of negotiating dominant ideologies. Their choice of institution is a key factor in the identity construction process, as it includes both accommodation and resistance to the dominant ideologies of their chosen institution (Rogers \& Way, 2018). A central focus of the study seeks to understand if there is a relationship to the type of institution participants attend and their access to Black historical knowledge. Therefore, this study does not disclose participant self-reported race/ethnicity data and focuses on institutional type.

\section{Research Design}

This study uses convergent parallel design. Both quantitative and qualitative strands were conducted in the same phase during the research process, with both methods equally prioritized. Data were analyzed independently; then results were compared and merged for interpretation (Creswell \& Plano Clark, 2018). "The collection and combination of both quantitative and qualitative data provides different insights, perspectives and a more complete understanding than what would have been provided by each database alone" (Creswell, 2014, p. 37). 
We utilized a survey research approach to explore students' responses to the NYT "1619 Project" article and podcast focused on Black contributions to American pop culture music. During a three-hour college course, students began the survey over a 45-minute period. The students engaged with the NYT 1619 Project material, then re-took surveys over another 45-minute period. The measurement instrument that was developed and used to test students' knowledge of Black music history was based on Black music history information found in the article and podcast. The instrument is composed of multiple choice questions, each of which has one correct answer. For example, one question asks, "Which of these is a major issue Whites had with Black artists? a. Black artists kept stealing and remaking the music of White artists; b. Once all Black people learned to read, they would eventually rule over White people; c. "Black culture" was becoming more popular and Whites were becoming obsolete; d. Black people were not purchasing enough goods and services from White people." The indices for both the pre-test and the post-test were computed by totaling the number of correct answers.

Emotional responses were measured after students engaged with the material. The questions dealing with emotion were measured using a 10-point agree-disagree scale. The eight-item scale included items that measured the intensity of eight different emotions. For example, one question asks, "To what degree did you feel hope during the article/podcast?" A higher score demonstrates a greater level of emotional response to the NYT 1619 Project material.

In addition, several open-ended questions were posed at the end of the survey. This study intentionally analyzes the six open-ended post assessment responses to provide a space for the participants to freely share their thoughts and feelings and to serve as a measure to expound upon the quantitative data collected. O'Cathain and Thomas (2004) suggest that open questions may help redress the power imbalance between researchers and respondents. However, this in turn obliges us to listen to what they say or read what they write. For example, one question asks, "During which points in the article/podcast did you experience the strongest emotion? Which emotion(s)? Why?" Themes were developed based on the coding of the open-ended responses. Scharrer \& Ramasubramanian (2015) found that qualitative approaches to the topic of media literacy education regarding race and ethnicity typically employ open-ended data gathering techniques and foreground the complex relationships between media consumers and media texts.

Both researchers analyzed the quantitative and qualitative data independently and then merged the results for interpretation in the discussion section.

\section{Quantitative Findings}

This section reports the quantitative results of the data analyses conducted to discover differences between both test scores and emotional responses at an HBCU and PWI. The quantitative data analysis explored the following research questions:

- Is there a relationship between the students' institution type and their emotional responses to NYT 1619 media? 
- Is there a relationship between students' institutional affiliation (HBCU or PWI) and pre-test level?

- Is there a relationship between students' institutional affiliation (HBCU or PWI) and post-test score level?

The first research question explores whether the institution type (HBCU or PWI) has a relationship with students' emotional response to NYT 1619 media. A correlation analysis was conducted to discover whether any relationships exist between institute type and emotions experienced while listening/hearing the 1619 information. The correlation analysis showed HBCU students felt more confident at times during the podcast. There was a positive correlation between the two variables, $r=.408, p=\leq .05$. Additionally, a relationship was found between HBCU students and feelings of pride $r=.483, p \leq$ .05. Although there were no significant relationships between PWI students and emotional response, the correlation analysis showed a relationship approaching significance with PWI students and shame $(r=.311, p=.083)$.

The second research question asked whether a relationship exists between the students' institution type and their pre-test level. A t-test was conducted to discover the difference, if any, between mean scores of the pre-test at the PWI and the HBCU. The ttest showed that there was no significant difference between the pre-test scores between the HBCU and the PWI.

The third research question asked whether a relationship exists between the students' institution type and their post-test level. A t-test was conducted to discover the difference, if any, between mean scores of the post-test at the HBCU and the PWI. The t-test showed a significant difference between post-test scores from the HBCU and the PWI. The HBCU post-test scores had a mean of (6.71), while the PWI scores averaged at (7.63). However, both HBCU students and PWI scored higher on the post-test than on the pretest.

\section{Qualitative Findings}

To further illustrate the quantitative results, this section reports the qualitative results of the data analyses conducted to understand the perspectives of HBCU and PWI students after engaging with NYT 1619 materials about Black music history. The qualitative data analysis addressed the following research question:

- How do college students experience learning underrepresented aspects of Black history through 1619 media based on institutional affiliation (HBCU or PWI)?

\section{Opportunities to Learn Underrepresented Aspects of Black History}

To gain a fuller understanding of the exposure of Black musical contributions as Black history, college students were asked to describe any experiences they had to engage with this particular topic in or outside of their institutional affiliation. Themes of home, personal education and school were the most prominent. 
While some students (7 responses) shared they had no opportunities to learn Black music as Black history, home and school were the predominant ways in which students engaged in this topic. Many HBCU and PWI students (13 responses) shared that they learned about Black music as Black history at home through family stories, family members, and listening to music, movies, and documentaries. Almost equally, students identified school as a place where they were exposed to Black music history (12 responses). Two students discussed learning this material at the $\mathrm{K}-12$ level. Judie (HBCU student) said she learned from her teachers, who primarily included resources beyond the set curriculum, that "they [several teachers] never used the textbook." Joe (PWI student) shared that he learned some of this material through US history in the 11th grade, as well as some early Black American composers in music classes. In contrast, Molly (PWI student) shared her feelings about not learning this material at all, saying, "It's just sad that this is a HUGE part of American history and we've never even learned about this before. Why is there so much hidden history?"

Primarily, students discussed opportunities to learn this history in college. Several HBCU students mentioned taking an African American Music course. Denise describes the content of the course this way:

During my African American music class, we went in depth about different generations of African American music, and also had to present to the class on different genres of music (example: jazz, ragtime, $r \& b$ ) and their contributors.

It's not just in music class. There seems to be a thread of Black history in many courses. Theresa (HBCU student), shares that "several courses task students with learning about the culture of African Americans. Courses on campus have given me the ability to learn about Black American musical contributions." While college courses in Black history are often major specific, HBCU students cited numerous opportunities to engage with Black music history beyond the classroom. One student, Denzel, said, "Literally everything, there is Black music all around us." HBCU students shared opportunities to learn Black history on campus from the African American museum, library, theater company, and general events on campus. Theresa further shared that students are urged across disciplines to attend musical performances and museums to learn more about Black history.

Though not as prominent as at the HBCU, some PWI students shared that they have, or at least are aware of, opportunities to engage in Black music history on campus. Benny shared that he attended jazz night, music concerts, and diversity week. However, most PWI students shared that they hadn't seen or attended many opportunities on campus that directly dealt with learning about Black American music.

Both HBCU and PWI students had a foundational awareness of Black music as Black history through family and popular culture (music, documentaries, and film). HBCU students identified their campus (mostly at the college level) as the predominant space where they received the most opportunities to engage in this material. They learned either through a specific course or access to other programming available at their institution. On the other hand, most PWI students lacked awareness of the few opportunities that did exist on campus. 


\section{Unpacking Racism Through Minstrel Shows}

A section of the NYT 1619 Project material presented the roots of American popular music through the lens of minstrelsy. Blackface minstrelsy was an established nineteenth-century theatrical practice, principally of the urban North, in which White men caricatured Blacks for sport and profit (Lott \& Greil, 2013). HBCU and PWI college students were asked to explain what they knew of minstrel shows before and after reviewing the NYT 1619 Project material.

Students (22 responses) in both contexts were loosely aware that minstrelsy involved entertainment and Blackface. However, the depth of students' prior knowledge about minstrelsy varied. Student responses ranged from no idea, or partial understanding, to more complete descriptions of the role of racism as entertainment and Blackface in minstrel shows. Four HBCU students and two PWI students shared that they didn't know or had no idea about minstrel shows. Several students demonstrated a partial understanding of minstrel shows as entertainment. Twelve HBCU and PWI students understood minstrel shows to be some form of entertainment, from either an underground music show, low budget performance, comedy, with most students describing a theatrical work. For example, Benny, a PWI student, described minstrels as "a circus type show." In eight of the 12 responses, there wasn't a clear identification of the entertainment as racist.

Most students (11 HBCU responses, 4 PWI responses) specifically named Blackface as a racist component of minstrelsy. However, results were mixed as to who performed Blackface. Some students identified Blackface performers as White in their comments. For example, Theresa, an HBCU student said, "When non-people of color impersonate African Americans by painting their faces Black." Another HBCU student Imani agreed and stated, "A minstrel show is when songs, dances, and theater plays are performed by Whites in Blackface." Alternatively, there were responses that noted Blackface performers as Black. KG, a PWI student said, "Minstrels are shows performed by African Americans to amuse Whites." An HBCU student, Monique, said "A (minstrel) show is where Black people dressed as Black people to make fun of Black people's actions." Few students were aware that both Black and White performers wore Blackface.

Semaj, an HBCU student, captured the complexity of both White and Black Blackface performers with her comment, "A (minstrel show) production put on by White people in Black face or a show where Blacks are made to be misrepresented." Hank, a PWI student, conveys a similar point in his description of minstrel shows with his use of "performers" when he says, "A combination of music and dancing where performers often wore Blackface to portray African Americans." They performed the act in a "comical way" with often goofy acting and dancing to portray people as "silly." Other students such as Denise (HBCU student) and Joe (PWI student) used the term "actors" and did not assign a race to Blackface performers.

Following the post-test (32 responses), most college students expressed a clearer understanding of Blackface minstrelsy as racist form of entertainment. Benny (PWI student), prior to engaging with NYT 1619 Project material, described minstrels simply as a circus type show, and then said, "Minstrels are a racist show objectifying Black culture." Similarly, Molly (PWI student), went from having no idea to saying, "A (minstrel) show put 
on by a White person, in Black face, to describe the life of Black people while entertaining an audience." Also, both HBCU and PWI students who conveyed a general knowledge of Blackface minstrelsy demonstrated a more nuanced understanding following engaging with NYT 1619 Project materials. One example is Joe (PWI student) who said, "A show, typically with Blackface, portraying a caricature of what White people (who usually never saw the south) thought Black culture was. The first form of American pop culture." Noel, an HBCU student, had expressed on the pre-test that minstrels portrayed Black people in a negative light. Afterwards, Noel described minstrels as "when a person wears Black face and represents the stereotypical idea of how Black people are."

Overall, students had varying levels of background knowledge involving racism in minstrelsy. Following their review of the NYT 1619 Project material, 28 of the 32 responses discussed minstrels as a form of racist entertainment.

\section{Emotional Responses to The New York Times 1619 Project Media}

Students were asked to identify specific instances when they experienced their strongest emotion during the article/podcast. Several students (8 responses) felt strong emotions overall. Most college students (11 responses) expressed feeling their strongest emotions during the discussion of minstrel shows. A number of students (7 responses) expressed feeling strong emotions when Motown was discussed. A smaller number (3 responses) described feeling no emotion. E, an HBCU student, shared, "I didn't feel any strong emotions because I am very desensitized to the topic of racism." Likewise, Rolfe, a PWI student, said, "I didn't even have a mild emotional reaction. I am aware enough to understand that America in 2019 is not representative of the world a few generations back. Black music was not the only thing the creators were able to profit off."

Further, college students were asked to describe the emotions they experienced when engaging with the NYT 1619 Project material. Positive (pride and happiness), negative (sadness, frustration, and anger) and mixed emotions emerged as themes. Some students (3 responses) described experiencing a range of feelings. Nester (PWI student) felt, "Some sad feelings then happy and hopeful." Two HBCU students, Diana and Jessica, described their mixed emotions more specifically. Diana said, "Of course, with the history of this country and the treatment of Blacks, I felt slightly irritated during the portion speaking about TD Rice. However, I felt mostly proud towards the end by the accomplishments of Black people." Jessica shared a similar sentiment, when she says, "I was upset that Black people did Blackface to be accepted and it still wasn't enough. I love that Black culture and music is still a world influencer today."

HBCU students predominantly ( 6 of 7 responses) experienced positive emotions. Charlie felt immense pride when finding out how powerful African Americans were. Tina reported beaming with pride when the strength of Black America was discussed. Queen, Trinity, and KG (PWI students) felt happiness as they read about and heard the music of Motown, as it was familiar. KG said, "I felt hope because you can feel it in your bones when you hear the music." As Denise, an HBCU student profoundly stated, "Blackness was on the move before my ancestors were legally free to be." 
Some college students also experienced negative emotions such as shame, sadness, and frustration. However, the type of negative emotion experienced by students varied by institution affiliation. Most PWI students who expressed negative emotions described a feeling of shame. An example of this is given by a Joe, a student at the PWI:

Learning about the minstrel shows and what they really were put me down a lot and made me feel extremely shameful, even though I know it wasn't me or generations of my family that had anything to do with it. It's just the fact that MY country used to be like that. We're used to being taught that the North wasn't nearly as racist as the South, yet here we are with creating minstrel shows and demeaning Blacks and Black culture even further.

HBCU students described feelings of frustration. Shane said, "I felt frustrated, during the whole thing. It was very annoying to see that White people and Black people wore Blackface." CiCi's comment highlights a similar feeling, when she says, "During the Blackface portion it was very degrading and insulting that White people saw it as entertainment."

Emotional responses to the 1619 Project material were varied including mixed, positive, and negative emotions. More HBCU students expressed positive emotions such as happiness and pride than negative emotions. PWI students expressed more negative emotions of shame than positive emotions. Overall, HBCU and PWI students in the study expressed both distinct and sometimes overlapping feelings with respect to the NYT 1619 Project material.

\section{Discussion}

The article and podcast situated Black music in a context that highlighted the tremendous progress Black musicians have made despite the inequality they have faced throughout history. We explored whether a relationship exists between institutional affiliation and students' emotional responses to 1619 Project media. The correlation analysis showed HBCU students felt higher pride and confidence while consuming the NYT 1619 media. This is supported in the open-ended responses, where many HBCU students expressed feelings of pride, happiness, and strength.

Many PWI students expressed the disparate emotion of shame. Most students had not consumed media texts as historically accurate and complete as the NYT 1619 Project in terms of representation of Black artists. It is quite possible that when students at the HBCU learned how Motown subverted the historical White supremacist culture, they saw "how radically optimistic a feat of antiminstrelsy" Motown's music was," (Morris, 2019, p.66) and discovered feelings of pride and confidence. Previous research suggests learning about Black history increases feelings of racial pride and self-esteem in Black students. (Stubbins, 2016). Bandura argued that a positive racial-ethnic identity builds a person's self-worth (1997).

We also explored whether knowledge of Black music history prior to engaging with the NYT 1619 Project material differed based on institutional affiliation (PWI and HBCU). The t-tests showed that pre-test scores between institutions weren't significantly different. This finding was surprising since HBCU students overwhelmingly felt they had numerous 
opportunities to learn about this topic at their institution. One might expect HBCU students to know more about Black musical history because of the greater emphasis on Black history, identity, and culture taught at an $\mathrm{HBCU}$, and therefore display a higher baseline score. "HBCUs generally seem to place a distinctive emphasis on formation of student identity, or self-concept, on at least three levels: racial/ ethnic, intellectual, and leadership" (Arroyo \& Gasman, 2014, p. 68). However, the similarity between pre-test scores does not support the idea that students at the HBCU know more about Black musical history, at least in this instance on this particular topic, than students at PWIs. It is also likely that prior to college, PWI and HBCU students in this study received years of $\mathrm{K}-12$ Black history education taught through the lens of Whiteness, which often is reductionist and neglects rich, complex topics. Teaching on this level is often limited and rarely involves the aspects of CRML that challenge students to reflect upon the deeply entrenched layers that privilege and position White contributions as superior. Perhaps, years of mainstream education ensured that both the PWI and HBCU students in this study had a similar and limited understanding of Black music history.

Additionally, we wanted to discover whether knowledge of Black music history after engaging with the NYT 1619 Project material differed based on institutional affiliation (PWI and HBCU). The t-tests showed that PWI students scored higher on the post-test than HBCU students. This was another surprising result. It was assumed that HBCU students would be more motivated to learn about Black musical history because of their connection with the material. HBCU students are explicitly taught their positive history as a way of overcoming the negative representations to which many students have been exposed. Stereotypes, negative portrayals, and underrepresentation in positive historical accounts all teach Black students that they have a lower value when compared with their White counterparts. At HBCUs, one explicit goal is to teach students to be proud of their Blackness (Arroyo \& Gasman, 2014). In their responses, most PWI students openly shared their lack of knowledge and opportunity to learn Black music history. Perhaps, since this topic may have contained a lot of new information, PWI students could have focused more on the content of the material in order to successfully answer more questions correctly.

The NYT 1619 Project is an example of CRML, as the piece itself did the social justice-related work of making previously unearthed history about Black music and musicians more accessible. Reading and listening to the NYT 1619 Project was an exercise in CRML for the students. Through it, students were able to think through the inaccuracies of the mainstream histories they had been taught. Students in both contexts reached the confrontation stage and realized they had been desensitized all these years to think that "American music" was primarily built on White American music. As a result of this dichotomy, students may have been shocked to learn the degree/level of Blacks' positive contribution to American Music history, resulting in feelings of hope and pride in some students and shame in others. Thus, the current study also shows how racial identity can be introduced or reinforced through CRML.

Overall, both groups of college students had roughly the same amount of background knowledge on Black music history as it relates to American popular culture. After engaging with the NYT 1619 Project material, both groups of college students had increased knowledge. While PWI students scored higher on the post-test, HBCU students 
conveyed more nuanced understandings of Black music history in their open responses. It is worth noting that both sets of students were eager to learn about the underrepresented aspects of Black music history. However, the PWI students faced a bigger challenge in learning the concepts because they were exposed to material that challenged their previous reality. Thus, they had more to gain. CRML emphasizes the ways in which race and racism are inescapable in multiple contexts. The theory explores how those issues affect a person's daily life. To many PWI students, race may not feel pervasive, particularly in music. Encountering the NYT 1619 Project could have given them a stronger inclination to navigate popular culture and its historical legacies rooted in racism. College students experienced confrontation and interrogation simultaneously, as they were exposed to problematic misrepresentation and erasure of Black culture in American music history.

In this study, HBCU students identified they are regularly exposed to racial inequalities juxtaposed with Black excellence and pride. While HBCU students reported learning details of Black music history, the overall concept of the NYT 1619 materials was not novel. Instead these were ideas to which they had already been exposed. Further, the NYT 1619 Project directly tied to the lived experiences of many HBCU students. Perhaps, HBCU students focused more on their emotional response as they experienced more varied emotions of pride, happiness, and frustration than PWI students who felt shame. HBCU students, by and large, shared more opportunities to engage with Black faculty, participate in race-themed lessons, and attend Black history and cultural events. For example, several HBCU students had taken a general education course called African American Music History. PWI students, on the other hand, noted limited opportunities to engage with Black histories on campus and may not have been accustomed to racebased education. Perhaps they performed better on the post-test because the information was novel to them.

\section{Conclusion}

This study focused on how educational media, such as the NYT 1619 podcasts and articles, can be analyzed through a Critical Race Media Literacy perspective. NYT 1619 Project material offers a critique of racism and exploitation in American popular music by centering Black music history as counterstory. It also illustrates how popular culture pedagogies could be used by college educators to teach historical contributions of Black, Indigenous and People of Color (BIPOC), as well as other underrepresented perspectives in higher education. "The degree to which a young person is able to learn about race via the school curriculum will inform their understanding of race-both its significance and impact in the present" (Brown \& Brown, 2015, p. 104).

This study gave students in two institutional contexts the opportunity to analyze their previous experiences with underrepresented areas of Black history. They also reflected on their opportunities in higher education and emotional responses to learning Black history, specifically Blackface minstrelsy. College students in both institutional contexts had varying levels of background knowledge and nuanced reactions to the media. Students at both types of institutions benefited from learning to analyze media through a Critical Race Media Literacy perspective. Through this lens, they were able to 
understand more broadly the ways in which societal systems of power affect the media they consume and history through historically themed pop-culture content. In the words of HBCU student B, "Black music is American music."

\section{Notes}

1. All proper names used are pseudonyms to protect the participants involved in this study as per guidelines stated in Interval Review Board (IRB) approval.

2. Blackface minstrelsy and minstrel shows are used interchangeably.

\section{References}

Agoosto, V., Karanxha, Z., \& Cobbs-Roberts, D. (2016). Critical race media literacy and incidents of retreating to teachable moments. In N.N. Croom \& T. E. Marsh (Eds.), Envisioning critical race praxis in higher education through counter storytelling (pp. 107-120). Information Age Publishing.

Akerlof, G. A., \& Kranton, R. E. (2010). Identity economics: How our identities shape our work, wages, and well-being. Princeton University Press.

Alvermann, D. E., \& Hagood, M. C. (2000). Critical media literacy: Research, theory, and practice in "new times." Journal of Educational Research, 93(3), 193-205.

Alvermann, D., Moon, J., \& Hagood, M. (1999). Popular culture in the classroom: Teaching and researching critical media literacy. Routledge.

Arroyo, A. T., \& Gasman, M. (2014). An HBCU-based educational approach for Black college student success: Toward a framework with implications for all institutions. American Journal of Education, 121(1), 57-85.

Bandura, A. (1997). The anatomy of stages of change. American Journal of Health Promotion: AJHP, 12(1), 8-10.

Bell, D. (1992). Faces from the bottom of the well: The permanence of racism. Basic Books.

Bergstrom, A., Flynn, M., \& Craig, C. (2018). Deconstructing media in the college classroom: A longitudinal Critical Media Literacy Intervention. Journal of Media Literacy Education, 10(3), 113-131. https://doi.org/10.23860/JMLE-2018-10-0307

Brown, A., \& Brown, K. (2015). The more things change, the more they stay the same: Excavating race and the enduring racisms in U.S. curriculum. Teachers College Record, 117(14), 103-130.

Buckingham, D. (2013). Media education: Literacy, learning and contemporary culture. John Wiley \& Sons.

Christian, M., Seamster, L., \& Ray, V. (2019). New directions in critical race theory and sociology: Racism, white supremacy, and resistance. American Behavioral Scientist, 63(13), 1731-1740. https://doi.org/10.1177/0002764219842623 
Cortes, C. (1987) A long way to go: Minorities and the media. Media \& Values, (38), Article 2. www.medialit.org/reading-room/long-way-go-minorities-and-media

Considine, D. (2002). Media literacy across the curriculum. Thinking critically about media, schools and families in partnership: Six perspectives and a conversation. http://www.medialit.org/reading-room/thinking-critically-about-media-schools-andfamilies-partnership

Considine, D. M., \& Haley, G. E. (1999). Visual messages: Integrating imagery into instruction (2nd ed.). Libraries Unlimited.

Creswell, J., \& Plano Clark, V. (2018). Designing and conducting mixed methods research (3rd ed.). SAGE Publications, Inc.

Creswell, J. W. (2014). A concise introduction to mixed methods research. SAGE Publications, Inc.

Delgado, R., \& Stefancic, J. (2017). Critical race theory: An introduction. (3rd ed., Critical America). New York University Press.

Dixson, A. D., \& Anderson Rousseau, C. (2018) Where are we? Critical Race Theory in education 20 years later. Peabody Journal of Education, 93(1), 121-131.

Durden, T., Dooley, C. M., \& Truscott, D. (2016). Race still matters: Preparing culturally relevant teachers. Race Ethnicity and Education, 19(5), 1003-1024.

Gainer, J. (2012). Critical thinking: Foundational for digital literacies and democracy. Journal of Adolescent \& Adult Literacy, 56(1), 14-17.

Guy, T. C. (2007). Learning who we (and they) are: Popular culture as pedagogy. New Directions for Adult and Continuing Education, 2007(115), 15-23. https://doi.org/10.1002/ace.263

Hawkman, A.M., \& Shear, S.B. (2017). They're gonna sing the songs anyway: Thinking and teaching with theory and Disney music for social studies. In W.B. Russell, III, \& K. S. Waters (Eds.), Cinematic social studies: A resource for teaching and learning social studies with film (pp. 55- 78). Information Age Press.

Hawkman, A. M., \& Van Horn, S. E. (2019). What does it mean to be patriotic? Policing patriotism in sports and social studies education. The Social Studies, 110(3), 105121. https://doi.org/10.1080/00377996.2018.1553841

Kellner, D., \& Share, J. (2005). Toward critical media literacy: Core concepts, debates, organizations, and policy. Discourse: Studies in the Cultural Politics of Education, 26(3), 369-386.

King, N. (2004). Using templates in the thematic analysis of text. In C. Cassell \& G. Symon (Eds.), Essential guide to qualitative methods in organizational research (pp. 257-270). SAGE Publications, Inc.

King, L. J. (2017a). The media and Black masculinity: Looking at the media through race[d] lenses. Critical Education, 8(2), 31-40.

King, L. J. (2017b). The status of Black history in U.S. schools and society. Social Education, 81(1), 14-18. 
King, L. J. (2019). Interpreting Black history: Toward a Black history framework for teacher education. Urban Education, 54(3), 368-396.

https://doi.org/10.1177/0042085918756716

Ladson-Billings, G., \& Tate, W. (1995). Toward a critical race theory of education. Teachers College Record, 97(1), 47-68.

Lott, E., \& Greil, M. (2013). Love and theft: Blackface minstrelsy and the American working class. Oxford University Press, Inc.

Luke, A. (2012). Critical literacy: Foundational notes. Theory into practice, 51(1), 4-11.

Morrell, E. (2002). Toward a critical pedagogy of popular culture: Literacy development among urban youth. Journal of Adolescent \& Adult Literacy, 46(1), 72-77.

Morrell, E., \& Duncan-Andrade, J. (2006). Popular culture and critical media pedagogy in secondary literacy classrooms. The International Journal of Learning: Annual Review, 12(9), 273-280. https://doi.org/10.18848/1447-9494/CGP/v12i09/48068

Morris, W. (2019, August 14). American popular music. The 1619 Project-The New York Times. Retrieved from https://www.nytimes.com/interactive/ 2019/08/14/magazine/1619-america-slavery.html

Nowell, L., Norris, J., White, D., \& Moules, N. (2017). Thematic analysis: Striving to meet the trustworthiness criteria. International Journal of Qualitative Methods, 16(1). doi:10.1177/1609406917733847

O'Cathain, A., \& Thomas, K. J. (2004). 'Any other comments?' Open questions on questionnaires - A bane or a bonus to research? BMC Medical Research Methodology, 4, 25-25.

Potter, W. J. (2013). Review of literature on media literacy. Sociology Compass, 7(6), 417-435.

Rodesiler, L. (2010). Empowering students through critical media literacy: This means war. The Clearing House, 83(5), 164-167.

Rogers, L. O., \& Way, N. (2018). Reimagining social and emotional development: Accommodation and resistance to dominant ideologies in the identities and friendships of boys of color. Human Development, 61(6), 311-331.

Scharrer, E., \& Ramasubramanian, S. (2015). Intervening in the media's influence on stereotypes of race and ethnicity: The role of media literacy education. Journal of Social Issues, 71(1), 171-185. https://doi.org/10.1111/josi.12103

Sellnow, D. D. (2017). The rhetorical power of popular culture: Considering mediated texts. SAGE Publications, Inc.

Semali, L. (2018). Intermediality: Teachers' handbook of critical media literacy. Routledge.

Shear, S.B. (2018). Teaching and learning using Indigenous-made films. Social Studies Journal, 38(2), 20-29.

Solórzano, D. G., Villalpando, O., \& Oseguera, L. (2005). Educational inequities and 
Latina/o undergraduate students in the United States: A critical race analysis of their educational progress. Journal of Hispanic Higher Education, 4(3), 272-294. http://doi.org/10.1177/1538192705276550

Solórzano, D. G., \& Yosso, T. (2002). Critical race methodology: Counter-storytelling as an analytical framework for education research. Qualitative Inquiry, 8(1), 23-44. doi:10.1177/107780040200800103.

Stubbins, Q. L. (2016). The effects of learning about Black history on racial identity, selfefficacy, self-esteem, and depression among low-income African American male youth (Publication No. 1026419) [Doctoral dissertation, Andrews University]. ProQuest Dissertations and Theses Global.

Taylor, E., Gillborn, D., \& Ladson-Billings, G. (Eds.). (2016). Foundations of critical race theory in education (2nd ed.). Routledge.

Yosso, T. J. (2002) Critical race media literacy: Challenging deficit discourse about Chicanas/os. Journal of Popular Film and Television, 30(1), 52-62.

Yosso, T. J. (2005). Whose culture has capital? A critical race theory discussion of community cultural wealth. Race Ethnicity and Education, 8(1), 69-91. http://doi.org/10.1080/1361332052000341006

\section{Author Contact}

Tiffany Mitchell Patterson: tiffany.mitchell@mail.wvu.edu

Department of Curriculum and Instruction/Literacy Studies, West Virginia University, PO Box 6201, Morgantown, West Virginia 26506

Christine McWhorter: camcwhorter@nsu.edu Department of Media, Journalism and Film, Howard University, 2400 6th St NW, Washington, DC 20059 